\title{
Health consumer expectations and perception of quality care services at primary health care level in Nigeria
}

\author{
Mohammed Saka, ${ }^{1}$ Tanimola Akande, ${ }^{1}$ Aishat Saka, ${ }^{2}$ Hassan Oloyede ${ }^{1}$ \\ ${ }^{1}$ Department of Epidemiology and Community Health,College of Health Sciences, University of Ilorin, \\ Ilorin; ${ }^{2}$ Department of Pediatric and Child Health, College of Health Sciences, University of Ilorin, Ilorin, \\ Nigeria
}

\begin{abstract}
The success of universal coverage of health at primary health care level depends on patient's perceptions or judgment on quality products and service rendered by the health personnel in the hospitals. Quality of health care services can be determined by gap between perception of what is offered in term of services and expectation from the health consumers. The study examined the expectations of health consumers and perception used in judging the quality of health care services at the primary health care level. A cross-sectional study was carried out among randomly selected
\end{abstract}

Correspondence: Hassan Oloyede, Department of Epidemiology and Community Health, Faculty of Clinical Sciences, College of Health Sciences, University of Ilorin, Ilorin Nigeria.

Tel.: +07032164184

E-mail: khassanuss@yahoo.com

Key words: Quality health care; expectation; perception; PHC.

Contributions: MS: data collecting and analyzing, manuscript writing manuscript reviewing; TA, AS: manuscript writing, manuscript reviewing; HO: references search, manuscript reviewing.

Conflicts of interest: The authors declare no conflict of interests.

Ethics approval and consent to participate: Ethical clearance was obtained from University of Ilorin ethical review committee. Protocol Identification code is UERC/CLS/007. Consent was obtained from the respondents. Informed sheets and consent forms were translated into relevant languages. Verbal consent was obtained prior to the survey, and all verbal consent was witnessed by a field worker.

Consent for publication: The patients gave their consent to publication.

Availability of data and materials: All data generated or analyzed during this study are included in this published article.

Received for publication: 11 November 2018

Revision received: 22 January 2021.

Accepted for publication: 22 January 2021.

This work is licensed under a Creative Commons Attribution NonCommercial 4.0 License (CC BY-NC 4.0).

C Copyright: the Author(s),2020

Licensee PAGEPress, Italy

Annals of African Medical Research 2020; $3: 55$

doi:10.4081/aamr.2020.55 health consumers that had received health care services in the hospitals designated as primary health care facilities in Kwara State Nigeria. Overall health consumers' means score expectations was 6.57 while perception was 5.80. Though was high in favour of females with no statistical significant difference. However, correlation test revealed significant association in socio-demographic variables such as age, occupation and educational status. Conversely, relationship was inverse in terms of increase in education attainment with lower perception value $(p<0.001)$. Expectation-perception gap was a major determinant of quality of health care services at primary health care levels. Significant relationship occurred between heath consumer's age, occupation, educational status and overall expectation-perception of quality health care received. It is recommended that hospital management need to monitor the link between the expectations including perception of services received by patients for quality improvement at primary health care level.

\section{Introduction}

Quality of health care involves offering technical competent, effective and safe care that contributes to the client's well-being, it is doing the right thing right, right away so as to meet the health consumer expectations, obtaining the best possible clinical outcome and maintaining positive perception of services. ${ }^{1}$

Expectations, with reference to healthcare, refer to the anticipation or the belief about what is to be encountered in a consultation or in the healthcare system. It is the mental picture that health consumers or the public will have of the process of interaction with the system. Every patient who comes for consultation has expectations based on his understanding of the illness, cultural background, health beliefs, and attitudes, level of understanding and socio-demographic characteristic of the health consumers. How far the physician reaches an understanding with the health consumers will also have an impact on the successful outcome of the consultation. ${ }^{2}$ Not meeting expectations can result in non-compliance, the health consumers may never complain to the physician directly but instead they just will not return for on-going and follow-up care..$^{3,4}$

Perceptions mean how health plans, hospitals, physicians, and health care in general are viewed currently by the health consumers. It is affected by i) the dominance of market-oriented approaches to reforms in health care delivery and cost; and ii) the emergence of a normative perspective on clinical practice that emphasizes the need to deliver health consumer-centred care. ${ }^{5}$ There are two perspectives on the important of patient perceptions of quality of health care, firstly, one can be normative that patient perceptions of quality are inherently meaningful and should be a primary focus of attention within the health care system. Secondly, one can take the position that we have to pay attention to patient 
perceptions because they are powerful drivers of outcomes important to various other stakeholders, outcomes such as patient choice of plan or provider, patient adherence to medical advice, ${ }^{6}$ patient complaints, grievances, ${ }^{7}$ the level and seriousness of malpractice claims, or, perhaps most important, actual health and functional status outcomes. ${ }^{8}$ Many researchers took both positions that patient perceptions have both inherent and instrumental value. ${ }^{9}$

Quality of health care services in the hospital is the discrepancy between patient's perceptions of services offered by a particular hospital and their expectations about hospitals offering such services. The patient's expectations are derived from their perception of the ideal care standards of their previous experiences in the use of services. ${ }^{10} \mathrm{~A}$ health customer that is satisfied will be more likely to continue to use the services, spread positive views that will help healthcare providers get new patients without additional cost such as advertising. ${ }^{11}$

Fundamentally, patients express their requirements in terms of what they need, want, prefer and demand with respect to the health care they receive. ${ }^{12}$ The requirements of patients could be considered as a demand for quality health care that health workers at primary level of health system attempt to meet. ${ }^{13}$ Excellence in health care is what those in need of healthcare services at the primary health care level wish for, and it is also the main goal for those providing the care. ${ }^{14}$ Given that the combined product of health consumers' expectations and perceptions determined quality of health care services, this study therefore examined the expectations and perception the health consumers used in judging the quality of care services at the primary health care level.

\section{Materials and Methods}

Kwara State was created in 1967 as one of the 36 federating units of Nigeria. It is in the North central geopolitical zone of the country. It has an estimated population of 2,371,000, with annual growth rate of $3.4 \%$. The Kwara State has 16 Local Government Areas grouped into 3 senatorial districts; the State capital is Ilorin. ${ }^{15}$ The public health service is organized into primary, secondary and tertiary health care levels. While the constitution is silent on the roles of the different levels of government in health services provision, the national health policy ascribes responsibilities for primary health care to local governments, secondary health care to states government and tertiary health care to the federal government. ${ }^{16}$ Primary health care (PHC), which forms the bedrock of the national health system, is the first level of care to the people. ${ }^{17}$

It was a community based cross sectional study using systematic sampling method to randomly selected 325 health consumers in selected primary health care facilities in Kwara State, Nigeria. Multistage sampling technique was adopted. First stage on the selection of primary health facility, all the Local Government Areas (LGAs) in the State were listed then all the primary health care facilities within the LGA in the State, from the listed PHC facilities in each LGA, two PHCs facilities were randomly selected by balloting and total of thirty-two PHCs facilities were randomly selected by balloting for the study.

In second stage on the selection of health consumers, in each of the selected primary health care facility all the service delivery areas/units were listed. The list also includes supportive service area of the hospital and service delivery department/units include but not limited to hospital reception area, emergency services unit, general outpatient department, immunization unit, maternal and child health unit, laboratory services and health record unit, etc. In each of these service delivery areas/units, the first client i.e. health consumer to be registered and attended to by the health care providers was selected; thereafter every $2^{\text {nd }}$ consecutive health consumers who had received any service or had at least one overnight stay and discharged in the hospital were randomly selected for interview in each service delivery point. However, health consumers that are in serious medical conditions that by virtue of illness will not be able to respond well to questions were excluded from study.

In the Measurements instruments used, the questions being asked comprises of open ended, dichotomous, rating and ranking questions. The tool was designed to elicit factual and definitive responses from the participants. The questionnaire was sectionalized into different parts of socio-demographic characteristics data, information on the respondents' perception and expectation of quality of health care services received. The research instrument was pre-tested among health consumers in other health institutions in Nigeria.

Research assistants made up of resident doctors, master students and medical students were recruited and trained for five days on data collection survey method. Proficiency of the interviewers was verified through role-play and pre testing. The researcher carried out visitation and checks in order to validate the collected data, each research assistant was recruited within the locality of the study site. Clearly define the outcome variables to be measured as products of the analysis, trained clerks entered the data from the interviews into the computer the same week the interviews are conducted and initially processed using excel then SPSS software version 20 packages were used for the analysis, $\mathrm{p}$ value, standard deviation and confident interval was calculated.

The qualitative section of the research was performed on oneto-one interviews with health consumers who had visited hospitals in the preceding six months especially women who delivered at the health facility. Three health consumers were interviewed in each PHC facility. Topics discussed include socio-cultural perception and expectation of quality health care services, feeling and if there any difference between the ways clients are treated. After each session, the tape recordings was transcribed and reconciled with the notes taken. The full recording was then edited to remove responses/session that was poorly transcribed. Finally, similar responses were group-coded, analyzed and presented.

After the ethical clearance from University of Ilorin ethical review committee, a letter of introduction was obtained from the department of epidemiology and community health, university of Ilorin, Ilorin. This was presented to the relevant authorities of the respective health Institutions that was selected requesting for their consent and participation in the study. During the surveys, consent was obtained from the respondents. Informed sheets and consent forms were translated into relevant languages. Verbal consent was obtained prior to the survey, and all verbal consent was witnessed by a field worker. All survey data was kept confidential. At each facility verbal consent was obtained to avoid suspicious of having to sign documents that may be used to identify them or their outlet/facility. Participants were allowed to drop out at any time during the survey and do not have to respond to questions they do not wish to answer. Ethical approval received from institution and protocol Identification code is UERC/CLS/007.

\section{Results}

This study response rate was $100 \%$, there were more females $300(92.3 \%)$ than male respondents, the predominant religious 
groups are Christianity and Islam accounting for 75 (23.1\%) and $250(76.9 \%)$ respectively. Married respondents are $175(53.8 \%)$ while $150(46.2 \%)$ were single. On educational status post-secondary education $175(53.8 \%)$ while others had secondary education $100(30.8 \%)$. Only $125(38.5 \%)$ of the respondents had monthly income of $\leq \$ 28.00$ (Table 1).

As seen in Table 2, explained positive perception 88 (27.1) and patient expectation 178(54.7) of total variance for medical doctor satisfaction scores. The clients had high positive expectation $223(68.5 \%)$ of the health facility premises but not much in difference on positive perception (61.6\%) and negative expectation $(61.0 \%)$ of diagnostic services. Other domains: disparity in positivity or negative expectations or perceptions in services quality the clients received from nurses, during admission to the hospital, the meals given to them with services received in the wards in Table 2. The reliability of the existence of quality gap in terms of overall perception (5.80) and expectations (6.57) of services is showed in Table 3.

An in-depth interview analysis of the tool showed that most of the patients were positive, such as "the service was good and doctors and nurses responded to questions quickly and completely." Though, prolonged waiting time, unpleasant smell of the reception area and young age of some nurses was an issues. In Table 4, the chi square test on gender showed no disparity in overall expectation-perception, though females had higher expectation than the male counterparts. Correlation test revealed significant changes in socio-demographic variables such as age, occupation, educational status and services quality variable examined. With increase in level of education there is decrease in perception scores of the clients $(p v=<0.001)$.

\section{Discussion}

Hospitals establishments like many other organizations are playing an increasingly important role that affects the health, wellbeing and economy of less-developed countries. One of the strong points of this study is the high percentage of responses, which reduces the non-response bias. This response rate was slightly
Table 1. Socio-demographic characteristic of the health consumers at PHC.

\begin{tabular}{|c|c|}
\hline Variable/Factors & $\begin{array}{c}\text { Frequency }(\%) \\
\quad(N=325)\end{array}$ \\
\hline $\begin{array}{l}\text { Age groups } \\
\quad \leq 30 \\
31-40 \\
41-50 \\
\quad 51-60 \\
\geq 61\end{array}$ & $\begin{array}{c}111(34.2)^{* *} \\
100(30.8) \\
56(17.2) \\
44(13.5) \\
14(4.3)\end{array}$ \\
\hline $\begin{array}{l}\text { Gender } \\
\text { Male } \\
\text { Female }\end{array}$ & $\begin{array}{l}25(7.7)^{* *} \\
300(92.3)\end{array}$ \\
\hline $\begin{array}{l}\text { Religion } \\
\text { Islam } \\
\text { Christianity } \\
\text { Traditional }\end{array}$ & $\begin{array}{c}250(76.9)^{* *} \\
75(23.1) \\
0(0\end{array}$ \\
\hline $\begin{array}{l}\text { Education Status } \\
\text { No Formal Educ. } \\
\text { Primary } \\
\text { Secondary } \\
\text { Post-Sec. }\end{array}$ & $\begin{array}{c}00(00.0) * * \\
50(15.4) \\
100(30.8) \\
175(53.8)\end{array}$ \\
\hline $\begin{array}{l}\text { Marital Status } \\
\text { Single } \\
\text { Married } \\
\text { Separated }\end{array}$ & $\begin{array}{c}150(46.2)^{* *} \\
175(53.8) \\
0(0)\end{array}$ \\
\hline $\begin{array}{l}\text { Occupation } \\
\text { Civil Servant } \\
\text { Self Employed } \\
\text { Unemployed } \\
\text { Farmers } \\
\text { Artisans } \\
\text { Students } \\
\text { Other } \\
\end{array}$ & $\begin{array}{c}75(23.1) * * \\
50(15.4) \\
80(24.6) \\
70(21.5) \\
50(15.4) \\
0(0.0) \\
0(0.0)\end{array}$ \\
\hline $\begin{array}{l}\text { Monthly Income (\$) } \\
\leq 28.00\end{array}$ & $125(38.5) *$ \\
\hline $\begin{array}{l}28.00-139.00 \\
139.00-270.00 \\
\geq 270.00\end{array}$ & $\begin{array}{c}125(38.5) \\
50(15.4) \\
25(7.6)\end{array}$ \\
\hline OVERALL Total & $325(100)$ \\
\hline
\end{tabular}

${ }^{*} \mathrm{p}<0.05 ;{ }^{*} \mathrm{p}<0.01 ;+\mathrm{p}=0.047 ; \# \mathrm{p}=0.05$ *variables significant for levels of care are highlighted. Mean age of $35.95 \pm 10.5$.

Table 2. Domains of quality of health care services health consumers' expectation - perception of services received.

\begin{tabular}{llllll} 
S/n & Domains variables & $\begin{array}{c}\text { Expectation positive } \\
\text { frequency (\%) }\end{array}$ & $\begin{array}{c}\text { Expectation negative } \\
\text { frequency (\%) }\end{array}$ & $\begin{array}{c}\text { Perception positive } \\
\text { frequency (\%) }\end{array}$ & $\begin{array}{c}\text { Perception negative } \\
\text { frequency (\%) }\end{array}$ \\
\hline 1 & Hospital premises and employees & $223(68.5)$ & $102(31.5)$ & $71(21.7)$ & $254(78.3)$ \\
2 & Quality of services from medical doctor & $178(54.7)$ & $147(45.3)$ & $88(27.1)$ & $237(72.9)$ \\
\hline 3 & Quality of diagnostic services & $125(38.4)$ & $200(61.6)$ & $198(61.0)$ & $127(39.0)$ \\
4 & Quality of services from nurses & $205(63.6)$ & $120(36.4)$ & $4(14.0)$ & $321(86.0)$ \\
\hline 5 & Quality of admission services & $316(97.3)$ & $9(2.7)$ & $37(11.1)$ & $288(88.9)$ \\
6 & Quality of meals \& laundry (ml) services & $106(32.6)$ & $219(67.4)$ & $215(66.4)$ & $110(33.6)$ \\
\hline 7 & House keeping services clinics, and wards & $177(54.3)$ & $148(45.7)$ & $24(7.2)$ & $301(92.8)$ \\
\hline
\end{tabular}

Table 3. Reliability and paired $\mathbf{t}$ test.

\begin{tabular}{lccc} 
Variables & Mean score & SD & t-test \\
Expectation & 6.57 & 0.234 & $1.08^{* *}$ \\
Perception & 5.80 & 0.135 & 0.947 \\
\hline
\end{tabular}

Note $*$ means significant at 0.05 level. 
higher than $99.9 \%$ rate of similar research in Latin American, ${ }^{18}$ and higher than the $63 \%$ in a study conducted among six hospital wards at the Academic medical centre, Amsterdam, with mean age of $35.95 \pm 10.5$, it implied that respondent's experiences are still recent enough for accurate recall and that majority of the respondents are within the reproductive age group (women of child bearing age). The pattern of age distribution of health consumers is in keeping with the population pyramid of most developing countries with a preponderance of the mid-aged compared with few elderly individuals WHO technical report series, ${ }^{19}$ there are more females than males this could be due to the fact that health care received at the primary health care in Nigeria was supported by midwives' services scheme programme of federal government as the cost of delivery was relatively free. Though, majority of the respondents are married which is keeping with national demographic health survey. ${ }^{20}$ However, significant difference observed in expectation and perception gaps in patient's age, occupation and income level, the results was different from study conducted among patients with refractive visual disorders. ${ }^{21}$

The higher proportion of Muslim respondents in this survey is not surprising because large percentages of people in study area are Muslims. The religious affiliation of the respondents is important since some beliefs about sickness and getting well were premised on the socio-cultural and religious practices of the individuals. Though, differ from other study, ${ }^{22}$ on traditional and religious practices affecting the health of other women in Nigeria that many

Table 4. Relationship between socio-demographic characteristics and patients expectation- perception on quality of health care services.

\begin{tabular}{|c|c|c|}
\hline Socio-demographic Variables & & \\
\hline & Expectation Freq.(\%) & Perception Freq. (\%) \\
\hline $\begin{array}{c}\text { Age Group } \\
\quad \leq 30 \\
31-40 \\
41-50 \\
51-60 \\
\geq 61 \\
\chi^{2} / p-v\end{array}$ & $\begin{array}{c}100(36.4) \\
100(36.4) \\
75(36.4) \\
0(0.0) \\
0(0.0) \\
27.330 /<0.001\end{array}$ & $\begin{array}{c}25(50.0) \\
0(0.0) \\
25(50.0) \\
0(0.0) \\
0(0.0)\end{array}$ \\
\hline $\begin{array}{c}\text { Gender } \\
\text { Male } \\
\text { Female } \\
2 / p-v \\
\end{array}$ & $\begin{array}{c}25(9.1) \\
250(90.9) \\
4.924 / 0.026\end{array}$ & $\begin{array}{c}0(0) \\
50(100.0)\end{array}$ \\
\hline $\begin{array}{l}\text { Religion } \\
\text { Islam } \\
\text { Christian } \\
\text { Other } \\
\chi^{2 / p-v}\end{array}$ & $\begin{array}{c}200(72.7) \\
75(27.3) \\
0(0) \\
17.727 /<0.001\end{array}$ & $\begin{array}{c}50(100.0) \\
0(0) \\
0(0)\end{array}$ \\
\hline $\begin{array}{l}\text { Edu status } \\
\text { None } \\
\text { Primary } \\
\text { Secondary } \\
\text { Tertiary } \\
\chi^{2 / p-v} \\
\end{array}$ & $\begin{array}{c}0(0) \\
50(18.2) \\
50(18.2) \\
175(63.6) \\
32.50 /<0.001\end{array}$ & $\begin{array}{c}50(100.0) \\
0(0) \\
0(0) \\
0(0)\end{array}$ \\
\hline $\begin{array}{l}\text { Marital St. } \\
\text { Single } \\
\text { Married } \\
\text { Separated } \\
\text { 2/p-v }\end{array}$ & $\begin{array}{c}100(36.4) \\
17(63.6) \\
68.939 /<0.001\end{array}$ & $\begin{array}{c}50(100.0) \\
0(0)\end{array}$ \\
\hline $\begin{array}{l}\text { Occupation } \\
\text { Civil.Serv. } \\
\text { Self Employed } \\
\text { Unemployed } \\
\text { Farmer } \\
\text { Artisan } \\
\text { Students } \\
\text { Other } \\
\chi^{2 / p-v} \\
\end{array}$ & $\begin{array}{c}175(63.6) \\
0(0) \\
75(27.3) \\
25(9.1) \\
0(0) \\
0(0) \\
0(0) \\
1.974 /<0.001\end{array}$ & $\begin{array}{c}0(0) \\
0(0) \\
0(0) \\
50(100.0) \\
0(0) \\
0(0) \\
0(0)\end{array}$ \\
\hline $\begin{array}{l}\text { Monthly IncomeX000 } \\
\quad \leq 10 \\
11-50 \\
501-100 \\
\geq 101 \\
\chi^{2 / p-v}\end{array}$ & $\begin{array}{c}50(22.2) \\
100(44.4) \\
50(22.2) \\
25(11.1) \\
27.778 /<0.001\end{array}$ & $\begin{array}{c}0(0) \\
25(100.0) \\
0(0) \\
0(0)\end{array}$ \\
\hline $\begin{array}{c}\text { In-Outpatient } \\
\text { Impatient } \\
\text { Outpatient } \\
\chi^{2 / p-v} \\
\end{array}$ & $\begin{array}{c}125(45.5) \\
150(54.5) \\
36.932 /<0.001\end{array}$ & $\begin{array}{c}0(0) \\
50(100.0)\end{array}$ \\
\hline
\end{tabular}


Muslims women are kept in purdah, during their reproductive years with social restrictions and low utilization of primary health care services in the hospital, utilization of primary health care services by many Muslim women may be supported with the fact that all the respondents interviewed were in one form of occupation or the other (Table 1). More than half of respondents had formal education, which is higher than the national figure of $43 \%$. Educational level is an important index of health status, wellbeing and provided greater access to health information. ${ }^{23}$

Though high expectation-perception gap was found in this study the use of only perceptions to determine quality of healthcare services was found in others studies ${ }^{24}$ conducted among nurses and dentists respectively, where it was reported that addition of expectations is unnecessary especially in the hospitals setting where expectations from healthcare providers usually range from high to very high due to the importance of all different dimension of the services provided in the hospital. In another study ${ }^{25}$ on a gap analysis of professional on quality of services, supported that use of only perceptions for determination of quality of services as it reveled recent events, problems or challenges in the establishment on services provided to the consumers, which will enhance immediate short-term solution than to start on long-term planning. However, this study was corroborated by study on customers' perception and expectation of primary health care services quality in health centres of Bandar Abbas ${ }^{26}$ found that periodic (e.g. quarterly, biannual or annually) collection of data on consumers' expectation can provide an insight for the long-term planning and improvement process for the hospital.

The results of comparing individuals' expectation-perception with the socio-demographic characteristics show significant effects (Table 4). For example, classification of educational level had significant effect on expectation-perception of clients at the significant level of $\mathrm{p}<0.05$ which may be due to the fact that health consumers with lower educational status had lower expectations of quality of healthcare services than the health consumers with tertiary education level. This study also found that women's expectation of quality of healthcare services was higher than that of the men expectation of quality of healthcare services. The women's higher expectations compared with the men had been reported in a study conducted on quality of screening service for chronic kidney-disease research evidence from Taichung City. ${ }^{27}$

Apart from socio-demographic characteristics effects on patients' expectation- perception of quality of healthcare, other study have shown that patients' expectations of quality of healthcare exceed perceptions of the healthcare as the patients felt that waiting time of more than an hour to receive the service was excessive and that the healthcare providers did not respond fast enough when problems arose in the hospitals. ${ }^{28}$ It was also found that expectation-perception gap enables healthcare providers to analyze the important of health services from the consumer perspective and to prioritized the areas or sections in the hospital that need immediate improvement for clients. Expectation-perception gap analysis of different domains in the hospital ensured proper allocation of resources starting with areas or units deemed most important for a short term than for long term.

The results of this research showed increase expectations of health consumer's in hospital premises and employees. Expectation from medical doctors and nurses working in the hospital at the primary health care level, quality of diagnostic services received from time of admission to wards and in the clinics. Overall respondent's expectation on quality of health care services received was more than average while perception of the services was less than one third. When compared with other studies con- ducted among patients in district hospitals and primary health centres in India ${ }^{29}$ the scores were less than the findings in this study.

There were extremely gaps in housekeeping services clinics and wards, nurses, and environmental premises. The reliability, assurance, and empathy were affected by the gaps. This study suggested that health workers should increase discussions and communication with their patients for satisfaction of services received as reported in other study. ${ }^{30}$

\section{Conclusions}

This study found that expectation- perception is a major determinant of quality of health care services at primary health care levels; there is disparity in expectation-perception gap among males and females respondents. However, significant relationship occurred in patients' age, occupation, educational status and overall expectation -perception of quality care received. Seven domains from receptions to service delivery points are identified as component parts of quality of health care services at primary health care level. The hospital management must also continuously monitor their services so as to strengthen quality of health care. Further study can be conducted among other health consumers receiving specialized care services in the hospital and from different health care providers. Behaviour variables and the methodology of this study can be easily adopted by the research team in the hospital to determine patient behaviours with service quality expectation.

\section{References}

1. Leebov W. The quality quest: a briefing for health-care professionals. Chicago: Hospital Publishing; 1991: pp.67-71.

2. Sun BC, Adams J, Orav EJ, et al. Determination of patients satisfaction and willingness to return with Emergency care. Ann Emerg Med 2000;38:426-34.

3. Hoy E. Measuring patient experiences of care. Bull Am CollSurg 2008;93:13-6.

4. Coulter A. After Bristol: putting patients at the centre. BMJ 2002;324:648-51.

5. Lewin SA, Skea ZC, Entwistle V, et al. Interventions for providers to promote a patient-centred approach in clinical consultations. Cochrane Database Syst Rev 2002;4:CD0 03267.

6. Bartlett JA. Addressing the challenges of adherence. J Acquir Immune DeficSyndr 2002;1:S2-10.

7. Taylor DM, Wolfe R, Cameron PA. Complaints from emergency department patients largely result from treatment and communication problems. Emerg Med 2002;14:43-9.

8. Covinsky KE, Rosenthal GE, Chren M, et al. The relation between health status changes and patient satisfaction in older hospitalized medical patients. J Gen Intern Med 1998;13:2239.

9. Jung HP, Wensing M, Olesen F, Grol R. Comparison of patients' and general practitioners' evaluations of general practice care. Qual Saf Health Care 2002;11:315-9.

10. Kucukarslan SN, Nadkarni A. Evaluating medication-related services in a hospital setting using the disconfirmation of expectations model of satisfactionl. ResSocAdmin Pharm 2015;4:12-22.

11. Zeithaml VA, Bitner MJ, Gremler DD. Services Marketing. New York, NY: McGraw-Hill, Inc; 2013:pp 49-51. 
12. Reck DL. Can and should nurses be aware of patients' expectations for their nursing care? NursAdm Q 2013;37:109-15.

13. Sayed HY, Mohamed HA, Mohamed EE. Patients' perceptions as indicators of quality of nursing service provided At Al noor specialist hospital at Makkah Al Moukarramah, KSA. J Am Sci 2013;9:71-8.

14. Abrahamsen Grøndahl V. Patients' perceptions of actual care conditions and patient satisfaction with care quality in hospital. Karlstad: Karlstads Universitet; 2012.

15. National Planning Commission. Children's and women's rights in Nigeria: A wake-up call. Situation Assessment and Analysis 2001.

16. Saka MJ, Isiaka SB, Akande TM, et al. Health related policy reform in Nigeria. Empirical analysis from 2001 to 2010; the past, trend and future directions for improved sustainable health and development. Int $\mathrm{J}$ Publ Admin Policy Res 2012;4;50-5.

17. Saka MJ, Saka AO, Oloriegbe IY. Overview of legal Implication and Health Consequences of Human Trafficking in Nigeria. Ilorin J Educ 2017;36:1-8.

18. Bankauskaite V, Saarelma O. Why are people dissatisfied with medical care services in Lithuania? A qualitative study using responses to open-ended questions. Int J Qual Health Care 2003;15:23-9.

19. WHO. Report of a WHO Expert Committee on Health of the Elderly. Demography and Public Health Aspects of Population Ageing. WHO Tech Rep Ser 1989;779:14-7.

20. National Planning Commission. Children's and women's rights in Nigeria: A wake-up call. Situation Assessment and Analysis 2001.

21. Deng-Juin L, Ing-Cheau S, Jar-Yuan P, Alex B, et al. Measuring patient's expectation and the perception of quality in LASIK services. Health Quality Life Outcomes 2013;7:63-7.
22. Johnson BC. Traditional practices affecting the health of women in Nigeria. In: Baasher T, Bannersman RH, Rushwan $\mathrm{H}$, et al. (eds). Traditional Practices Affecting the Health of Women and Children. Alexandria, Egypt: WHO; 1982: pp. 235 .

23. Saka MJ, Abdul FI, Saka AO, et al. Assessment of Infrastructure and Community Supply in Nigeria Private Health Facilities: Implication on the implementation for Maternal and Child health Care Policies. Tropical J Health Sci 2012;19;31-4.

24. Paul PD. What is the best approach for measuring service quality of periodontists? Clinical ResRegulatory Affairs 2003;20:457-68.

25. Brown SW,Swartz TA. A Gap Analysis of Professional Service Quality. JMark 1989;53:92-8.

26. Aghamolaei T, Zare SH, Poudat A, Kebriyaei A. Customersperceptionand expectation of primary health care services quality in health centers of Bandar Abbas. Hormozgan Univ Med Sci J 2007;3:173-9.

27. DengJuin L, YaHsin L, JarYuan P, et al. Chronic kidney-disease screening service quality: questionnaire survey research evidence from Taichung City. BMC Health Serv Res 2009;9:239.

28. Suki NM, Lian JCC, Suki NM. Do patients 'perceptions exceed their expectations in private healthcare settings? Int J Health Care QualAssurrance 2011;24:42-56.

29. Lin HC, Sudha X, Laditka JN. Perceptions of service quality in group versus solo practice clinics. Int J Qual Health Care 2014; 16:437-45.

30. Chen JY, Tao ML, Tisnado D, et al. Impact of PhysicianPatient Discussions on Patient Satisfaction. Medical Care 2013;46:1157-62. 